\title{
Vitamin $D$ and responses to inhaled fluticasone in severe chronic obstructive pulmonary disease
}

This article was published in the following Dove Press journal:

International Journal of Chronic Obstructive Pulmonary Disease 6 January 2011

Number of times this article has been viewed

\author{
Ken M Kunisaki ${ }^{1,3}$ \\ Thomas S Rector ${ }^{2,4}$ \\ 'Pulmonary Section, ${ }^{2}$ Center for \\ Chronic Disease Outcomes Research \\ and Center for Epidemiologic \\ and Clinical Research, Minneapolis \\ Veterans Affairs Medical Center, \\ Minneapolis, MN, USA; ${ }^{3}$ Division \\ of Pulmonary, Allergy, Critical Care \\ and Sleep Medicine, ${ }^{4}$ Department \\ of Medicine, University of Minnesota, \\ Minneapolis, MN, USA
}

Background: Patients with chronic obstructive pulmonary disease (COPD) demonstrate variable responses to inhaled corticosteroids (ICS). The factors contributing to this variability are not well understood. Data from patients with asthma have suggested that low 25 -hydroxyvitamin $\mathrm{D}[25(\mathrm{OH}) \mathrm{D}]$ levels contribute to a lack of ICS response in asthma. The objective of this study was to determine whether serum levels of $25(\mathrm{OH}) \mathrm{D}$ were related to ICS responses in patients with COPD.

Methods: A total of 60 exsmokers with severe COPD (mean forced expiratory volume in one second $\left[\mathrm{FEV}_{1}\right] 1.07 \mathrm{~L}, 36 \%$ of predicted) spent 4 weeks free of any ICS, followed by 4 weeks of ICS use (fluticasone propionate $500 \mu \mathrm{g}$ twice daily). Spirometry was performed prior to and after 4 weeks of ICS use. Blood 25(OH)D levels were measured prior to ICS use and examined for relationships to changes in $\mathrm{FEV}_{1}$ following the 4 weeks of ICS use.

Results: The mean 25(OH)D level was $23.3 \pm 9.3 \mathrm{ng} / \mathrm{mL}$. There was a high prevalence of vitamin D insufficiency (35\%) and deficiency (40\%). There was no relationship between baseline 25(OH)D and changes in $\mathrm{FEV}_{1}$ following 4 weeks of ICS.

Conclusion: Baseline 25(OH)D does not contribute to the variation in short-term $\mathrm{FEV}_{1}$ responses to ICS in patients with severe COPD.

Keywords: COPD, androstadienes, anti-inflammatory agents, spirometry

\section{Introduction}

Vitamin D has received increasing amounts of attention in recent years, particularly its potential nonskeletal effects in diseases such as cancer, cardiovascular disease, and infectious diseases. Although an optimal level of vitamin $\mathrm{D}$ has not been defined for nonskeletal outcomes, 25-hydroxyvitamin D [25(OH)D] levels $<20 \mathrm{ng} / \mathrm{mL}$ are widely considered to reflect deficiency. Using this definition, patients with chronic obstructive pulmonary disease (COPD) have a high prevalence of vitamin $\mathrm{D}$ deficiency, ranging from approximately $30 \%$ in mild COPD to over $75 \%$ in severe COPD. ${ }^{1-5}$ The clinical consequences of these low 25(OH)D levels in COPD patients have not been studied extensively. Among patients with asthma, low 25(OH)D levels have been associated with an increased risk of severe asthma exacerbations, ${ }^{6}$ hospitalizations, ${ }^{7}$ poor asthma control, ${ }^{8}$ and steroid resistance. ${ }^{9}$ We pursued the current study to investigate relationships between $25(\mathrm{OH}) \mathrm{D}$ and responses to inhaled corticosteroid (ICS) treatment in patients with COPD.

ICS are widely used in the treatment of COPD. However, the clinical response to ICS is variable, and some patients respond more favorably than others. The underlying causes of this variable response are not well understood. Recent data from patients
Correspondence: Ken M Kunisaki Minneapolis VA Medical Center, Pulmonary Section (IIIN),

One Veterans Drive, Minneapolis,

MN, 55417, USA

Tel + I 6124674400

Fax + I 6127275634

Email kunis00I@umn.edu 
with asthma suggest that low blood $25(\mathrm{OH}) \mathrm{D}$ levels might contribute to poor glucocorticoid responses. ${ }^{10,11}$ We therefore examined the hypothesis that among patients with COPD, 25(OH)D levels were associated with the variation in responsiveness to ICS treatment.

\section{Methods}

This study was conducted using stored serum from a previous study designed to examine the ability of exhaled nitric oxide and blood markers of systemic inflammation to predict forced expiratory volume in one second $\left(\mathrm{FEV}_{1}\right)$ responses to ICS treatment in patients with COPD. Results have been previously published. ${ }^{12}$

\section{Subjects}

The institutional review board of the Minneapolis Veterans Affairs Medical Center approved the original study and this secondary analysis. All subjects provided written informed consent for the original study and for storage of blood samples for future research. The study did not meet trial registration criteria at the time of its conduct between 2005 and 2006.

Subjects were recruited from the Minneapolis Veterans Affairs Medical Center between May 2005 and February 2006. Inclusion criteria were: 1) a clinical diagnosis of $\mathrm{COPD}$, with a $\mathrm{FEV}_{1} /$ forced vital capacity (FVC) ratio $<70 \%$, and $\mathrm{FEV}_{1}<60 \%$ of predicted; 2 ) age $>45$ years; 3 ) cigarette smoking history of $>10$ pack-years; 4 ) abstinence from cigarette smoking of at least 6 months; 5) stable clinical status, as evidenced by the lack of hospitalizations, urgent care visits, antibiotics, or changes in medications within 4 weeks prior to enrollment; and 6) ability to provide informed consent. Exclusion criteria were: 1) a clinical diagnosis of asthma; 2) leukotriene inhibitor use; 3) severe or uncompensated heart failure; 4) the presence of conditions known to elevate C-reactive protein (CRP) levels such as collagen vascular disease and chronic infection; 5) malignancy requiring active treatment with chemotherapy or radiation therapy, or any comorbidity making survival longer than 1 year unlikely; 6) women who were pregnant or lactating; 7) oral corticosteroid use within 4 weeks prior to enrollment; and 8) participation in another investigational trial within 4 weeks of enrollment and for the 8-week duration of this study.

\section{Study design}

Subjects who met study criteria and agreed to participate entered a 4-week run-in period. During the run-in, subjects were treated with salmeterol, $50 \mu \mathrm{g}$ inhalation twice daily
(Serevent Diskus ${ }^{\circledR}$; GlaxoSmithKline, Research Triangle Park, NC). The use of ICSs was not allowed during the run-in. Tiotropium use was not allowed for the duration of the study; however, tiotropium was not in wide use at the time of this study. Subjects were allowed to continue use of all other respiratory medications, including short-acting beta agonists and ipratropium.

After the run-in, subjects returned to the study center for baseline measurements of prebronchodilator spirometry and blood collection. All visits were in the morning and subjects were fasting. Before each study visit, subjects withheld use of short-acting bronchodilators for 6 hours and withheld use of salmeterol for 12 hours. For the next 4 weeks, subjects were treated twice daily with $500 \mu \mathrm{g}$ of fluticasone propionate and $50 \mu \mathrm{g}$ of salmeterol (Advair Diskus 500/50 ${ }^{\circledR}$; GlaxoSmithKline). After 4 weeks, subjects returned to the study center for repeat measurement of prebronchodilator spirometry and blood sample collection.

\section{Protocols}

Spirometry was performed in accordance with American Thoracic Society (ATS) standards ${ }^{13}$ (MicroLab 3500, MicroMedical, Kent, UK). Third National Health and Nutrition Examination Survey spirometric reference values were used as reference. ${ }^{14}$

Serum blood samples were allowed to clot at room temperature, centrifuged, and immediately frozen at $-80^{\circ} \mathrm{C}$ in aliquots. Stored serum for $25(\mathrm{OH}) \mathrm{D}$ assay was available for all patients who completed the original study. For this study, 25(OH)D levels were measured from stored samples collected at the visit following the run-in ("baseline"), prior to ICS initiation. $25(\mathrm{OH}) \mathrm{D}$ was measured by liquid chromatography tandem mass spectroscopy (ThermoFisher Scientific, Franklin, MA; Applied Biosystems-MDS Sciex, Foster City, CA) at the Mayo Clinic Immunochemical Core Laboratory (Rochester, MN).

\section{Statistical methods}

The primary outcomes of interest in the original study were correlations between potential predictor variables (exhaled breath and blood inflammatory markers) and the outcome variable: prebronchodilator change in $\mathrm{FEV}_{1}$ from baseline to after 4 weeks of ICS therapy. The study was powered (two-sided alpha of 0.05 and beta of 0.20 ) to detect a correlation coefficient of 0.35 . This resulted in a sample size calculation of 62 patients. Seventy-eight subjects consented, which allowed for $20 \%$ of consented subjects to either fail spirometry screening or not complete the full protocol. 
This secondary analysis of $25(\mathrm{OH}) \mathrm{D}$ levels as a predictor variable of ICS response was not planned at the time of the original study.

Because ICS responses were not normally distributed, analyses were conducted with nonparametric statistical tests. For the primary correlation analyses, Spearman's rank-correlation testing (reported as Spearman's rho) was used. For secondary analyses, we dichotomized subjects into responders and nonresponders to ICS therapy, using a FEV improvement of $\geq 200 \mathrm{~mL}$ after 4 weeks of ICS therapy to define responders. There is no consensus on a meaningful $\mathrm{FEV}_{1}$ response to ICS therapy in COPD. We thus extrapolated from ATS guidelines which require $\geq 200 \mathrm{~mL}$ improvement in $\mathrm{FEV}_{1}$ as a component of defining a significant bronchodilator response. ${ }^{13}$

Distributions of $25(\mathrm{OH}) \mathrm{D}$ among responders and nonresponders were compared using the Wilcoxon rank-sum test. Receiver-operating characteristic (ROC) analyses were also conducted, using $\mathrm{FEV}_{1}$ improvement of $\geq 200 \mathrm{~mL}$ after 4 weeks of ICS therapy as the outcome of interest. We also dichotomized subjects using conventional 25(OH)D cut points for vitamin D deficiency $(<20 \mathrm{ng} / \mathrm{mL})$ and insufficiency $(<30 \mathrm{ng} / \mathrm{mL})$ and compared distributions of $\mathrm{FEV}_{1}$ change using the Wilcoxon rank-sum test.

All statistical analyses were performed using Stata software (v. 9; StataCorp LP, College Station, TX).

\section{Results}

A total of 76 patients consented to study participation, and $16(21 \%)$ did not complete the full protocol. Three failed to meet screening spirometry criteria, seven experienced COPD exacerbations during the study, and six withdrew consent during the study, chiefly for subjective dyspnea. Therefore, 60 patients provided complete data for analysis. Compared to participants who completed the study, participants who withdrew from the study had similar COPD severity, but were more likely to have been prescribed antibiotics and prednisone in the previous 12 months, and were more likely to have received more inhaled medications, including inhaled corticosteroids, before study participation (Table 1).

The mean age was 71 years (98\% males), with a mean $\mathrm{FEV}_{1}$ of $1.07 \mathrm{~L} \pm 0.36 \mathrm{~L}$ (36\% of predicted). ICS compliance was excellent ( $93 \%$ of expected doses used) as assessed by device dose delivery counters. FEV 1 change after ICS treatment ranged from -0.49 to $0.64 \mathrm{~L}$ (median change of $0.07 \mathrm{~L}$; interquartile range, $-0.02-0.14 \mathrm{~L}$ ). Mean $25(\mathrm{OH}) \mathrm{D}$ level was $23.3 \pm 9.3 \mathrm{ng} / \mathrm{mL}$. There was no correlation between baseline $25(\mathrm{OH}) \mathrm{D}$ levels and baseline $\mathrm{FEV}_{1}$
(Spearman rho $=-0.10 ; P=0.46)$ (Figure 1). There was a high prevalence of vitamin D deficiency $(n=24 ; 40 \%)$ when using the standard definition of deficiency being a 25(OH)D level $<20 \mathrm{ng} / \mathrm{mL}$. Vitamin D insufficiency, defined as a $25(\mathrm{OH}) \mathrm{D}$ level $\geq 20 \mathrm{ng} / \mathrm{mL}$ but $<30 \mathrm{ng} / \mathrm{mL}$, was also prevalent $(n=21,35 \%)$. Only $25 \%$ of study participants had a $25(\mathrm{OH}) \mathrm{D}$ level considered normal.

There was no correlation between baseline 25(OH)D and subsequent $\mathrm{FEV}_{1}$ responses to ICS (Spearman rho $=0.01$; $P=0.93$ ) (Figure 2). When ICS responders were defined as experiencing $\geq 200 \mathrm{~mL}$ improvement in prebronchodilator $\mathrm{FEV}_{1}$ between baseline and after ICS therapy, the median baseline $25(\mathrm{OH}) \mathrm{D}$ of ICS responders $(\mathrm{n}=11)$ and nonresponders $(\mathrm{n}=49)$ was equal $(23 \mathrm{ng} / \mathrm{mL}$ and $23 \mathrm{ng} / \mathrm{mL}$, respectively; Wilcoxon rank-sum, $P=0.97$ ) (Figure 3 ). ROC analysis showed that $25(\mathrm{OH}) \mathrm{D}$ had no ability to discriminate ICS responders from nonresponders (ROC area under curve $=0.50 ; 95 \%$ confidence interval: $0.31-0.68$ ) When patients were dichotomized as vitamin $\mathrm{D}$ deficient $(25[\mathrm{OH}] \mathrm{D}<20 \mathrm{ng} / \mathrm{mL})$ or not deficient, there was no difference in the median $\mathrm{FEV}_{1}$ improvement with ICS in each group $(75 \mathrm{~mL}$ and $50 \mathrm{~mL}$, respectively; Wilcoxon rank-sum, $P=0.64)$ (Figure 4). Results did not change when the $25(\mathrm{OH})$ D cutoff was changed to $<30 \mathrm{ng} / \mathrm{mL}$ to compare those with vitamin $\mathrm{D}$ insufficiency or deficiency to those with normal vitamin D levels (median $\mathrm{FEV}_{1}$ improvement of $80 \mathrm{~mL}$ and $50 \mathrm{~mL}$, respectively; Wilcoxon rank-sum, $P=0.78$ ).

\section{Discussion}

This study utilized stored samples from a previous study examining predictors of ICS responses in patients with COPD. In the original study, exhaled nitric oxide was shown to have a modest relationship to ICS responses. In this secondary analysis of stored samples from that study, baseline 25(OH)D had no relationship to $\mathrm{FEV}_{1}$ changes after 4 weeks of ICS use.

This secondary analysis was largely prompted by Sutherland and colleagues' findings. ${ }^{10}$ In their sample of 54 adults with asthma, low 25(OH)D levels were associated with blunted corticosteroid responses. However, corticosteroid responses in their study were assessed by an in-vitro assay of dexamethasone-induced mitogen-activated protein kinase phosphatase (MKP)-1 expression by peripheral blood mononuclear cells (PBMCs), rather than spirometry. As such, the clinical extension of their in vitro finding remains to be validated. In a related study of 100 children with asthma, Searing and colleagues reported similar in vitro effects of vitamin D on dexamethasone-induced MKP-1 expression by PBMCs. ${ }^{11}$ Relationships between vitamin D and steroid 
Table I Characteristics of study sample at time of enrollment

\begin{tabular}{|c|c|c|}
\hline Baseline characteristics at screening & $\begin{array}{l}\text { Completed study } \\
(n=60)\end{array}$ & $\begin{array}{l}\text { Withdrawn from study } \\
(n=\mid 3)\end{array}$ \\
\hline \multicolumn{3}{|l|}{ Demographics and smoking history } \\
\hline Male & $59(98 \%)$ & $13(100 \%)$ \\
\hline Female & I (2\%) & $0(0 \%)$ \\
\hline Age (years) & $71 \pm 7.3$ & $70 \pm 7.9$ \\
\hline Smoking history (pack-years) & $57 \pm 30.6$ & $53 \pm 26.1$ \\
\hline Duration of smoking abstinence (years) & $13 \pm 10$ & $13 \pm 9.4$ \\
\hline \multicolumn{3}{|l|}{ Spirometry } \\
\hline Prebronchodilator $\mathrm{FEV}_{1}(\mathrm{~L})$ & $1.07 \pm 0.36$ & $1.09 \pm 0.28$ \\
\hline Prebronchodilator $\mathrm{FEV}$ (\% predicted) & $35.6 \pm 10.6$ & $33.0 \pm 8.5$ \\
\hline Prebronchodilator FVC (L) & $2.44 \pm 0.72$ & $2.54 \pm 0.62$ \\
\hline Prebronchodilator FVC (\% predicted) & $58.5 \pm 14.6$ & $56.8 \pm 12.9$ \\
\hline \multicolumn{3}{|l|}{ Medication use } \\
\hline Prescribed one or more courses of antibiotics in the & II (18\%) & $6(46 \%)$ \\
\hline \multicolumn{3}{|l|}{12 months prior to enrollment } \\
\hline Prescribed one or more courses of prednisone in the & $7(12 \%)$ & $6(46 \%)$ \\
\hline \multicolumn{3}{|l|}{12 months prior to enrollment } \\
\hline Prescribed chronic oxygen & $10(16 \%)$ & $3(23 \%)$ \\
\hline Prescribed albuterol & $59(98 \%)$ & $12(92 \%)$ \\
\hline Prescribed ipratropium & $35(58 \%)$ & II (84\%) \\
\hline Prescribed long-acting beta agonist & $30(50 \%)$ & $9(69 \%)$ \\
\hline Prescribed long-acting anticholinergic & I (2\%) & $0(0 \%)$ \\
\hline Prescribed inhaled corticosteroid & $28(47 \%)$ & $9(69 \%)$ \\
\hline Prescribed theophylline & $2(3 \%)$ & $0(0 \%)$ \\
\hline \multicolumn{3}{|l|}{ Comorbid conditions } \\
\hline Coronary artery disease & $16(27 \%)$ & I (8\%) \\
\hline Heart failure & $6(12 \%)$ & I (8\%) \\
\hline Hypertension & $36(60 \%)$ & $8(62 \%)$ \\
\hline Atrial fibrillation/flutter & $5(8 \%)$ & $0(0 \%)$ \\
\hline Hyperlipidemia & $37(62 \%)$ & $8(62 \%)$ \\
\hline Diabetes mellitus & $14(23 \%)$ & $\mathrm{I}(8 \%)$ \\
\hline Peripheral vascular disease & $9(15 \%)$ & $\mathrm{I}(8 \%)$ \\
\hline History of stroke & $2(3 \%)$ & $0(0 \%)$ \\
\hline Chronic kidney disease & $5(8 \%)$ & $0(0 \%)$ \\
\hline Obstructive sleep apnea & $4(7 \%)$ & $0(0 \%)$ \\
\hline Gastroesophageal reflux disease & $12(20 \%)$ & I (8\%) \\
\hline Chronic rhinosinusitis & $5(8 \%)$ & I (8\%) \\
\hline
\end{tabular}

Note: Data are presented as mean \pm standard deviation for continuous variables or as number (\%) for categorical variables.

Abbreviations: $\mathrm{FEV}_{1}$, forced expiratory volume in I second; FVC, forced vital capacity.

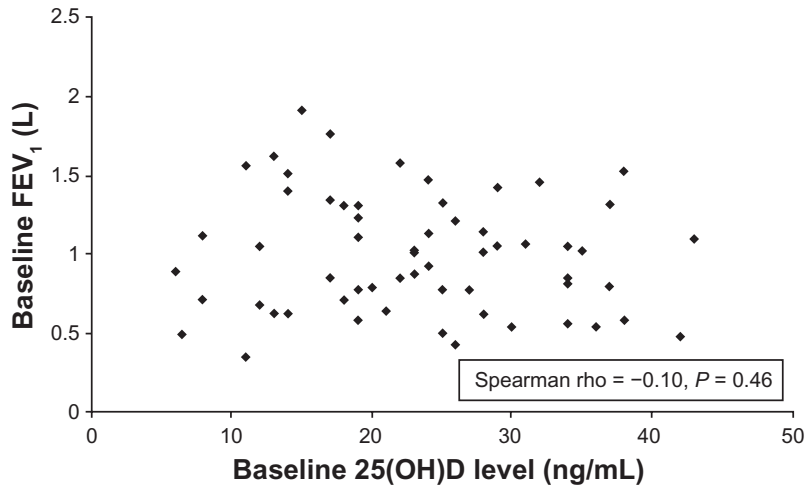

Figure I Scatterplot of baseline (pre-ICS) 25(OH)D and baseline pre-bronchodilator $\mathrm{FEV}_{1}$. Spearman's rank-correlation test used for calculation of Spearman rho and corresponding $P$ value.

Abbreviations: $25(\mathrm{OH}) \mathrm{D}, 25$-hydroxyvitamin $\mathrm{D}$; $\mathrm{FEV}_{\text {, }}$, forced expiratory volume in I second; ICS, inhaled corticosteroid.

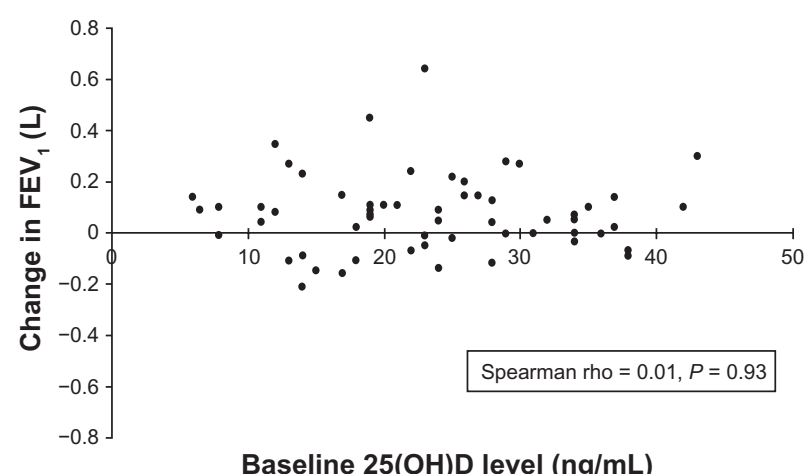

Figure 2 Scatterplot of baseline (pre-ICS) 25(OH)D and change in prebronchodilator $\mathrm{FEV}$, following 4 weeks of ICS. Spearman's rank-correlation test used for calculation of Spearman rho and corresponding $P$ value.

Abbreviations: $25(\mathrm{OH}) \mathrm{D}, 25$-hydroxyvitamin $\mathrm{D}$; $\mathrm{FEV}_{1}$, forced expiratory volume in I second; ICS, inhaled corticosteroid. 


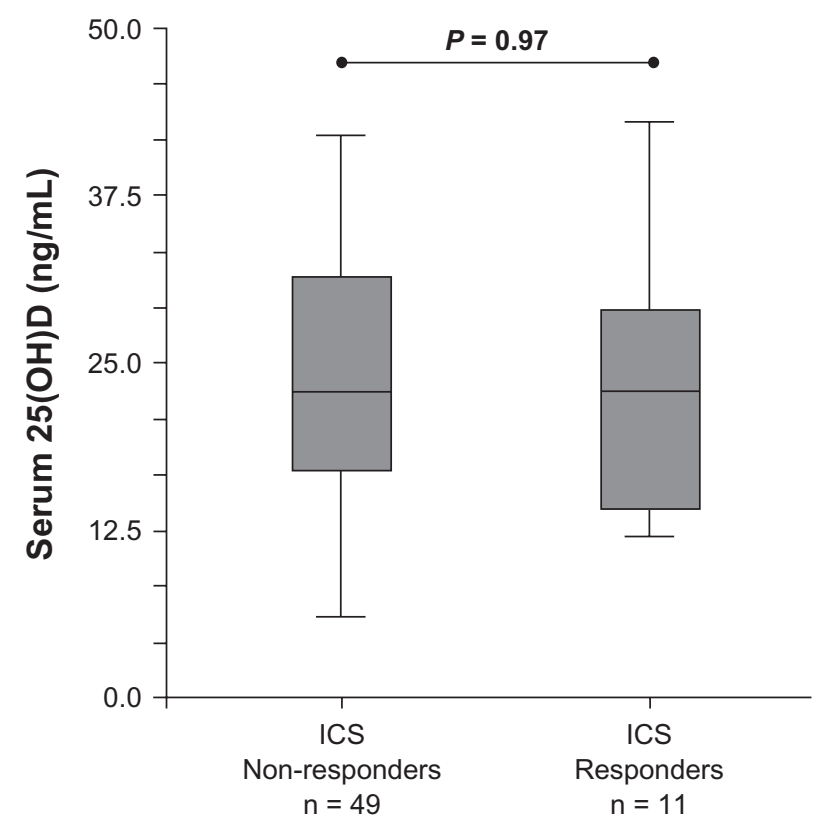

Figure 3 Boxplots of baseline (pre-ICS) 25(OH)D distributions among ICS nonresponders and ICS responders. ICS responders were defined as experiencing $\geq 200 \mathrm{~mL} \mathrm{FEV}$, improvement following 4 weeks of ICS. Wilcoxon rank-sum test used for calculation of $P$ value.

Abbreviations: 25(OH)D, 25-hydroxyvitamin D; FEV , forced expiratory volume in I second; ICS, inhaled corticosteroid.

responses may be different in asthma and COPD, but there are currently no published reports regarding this topic among patients with COPD.

This is the first study to analyze $25(\mathrm{OH}) \mathrm{D}$ levels in relation to ICS responses in COPD. This study has several limitations. The study sample was essentially limited to elderly Caucasian males and was a single-center study. Our study was also relatively small in size, but all of our point estimates for differences clustered around the null hypothesis of no difference. As such, a larger sample size would not likely alter the conclusions. In addition, $\mathrm{FEV}_{1}$ responses were only assessed over a relatively brief 4-week ICS intervention; longer-term outcome data were not collected. The rationale for this brief intervention was that the majority of ICS effects on $\mathrm{FEV}_{1}$ have occurred within 2-4 weeks in previous large COPD clinical trials. ${ }^{15-17}$

The need for an ICS wash-out period may have also affected our results. Patients with previous good clinical responses to ICS therapy may have been either less likely to enroll in this study or more likely to withdraw during the study, as was suggested by the higher percent of previous ICS users in the group that did not complete the study. Thus, our sample may have been biased towards ICS nonresponders. A 4-week period for ICS wash-out could also limit ICS responses following re-introduction of ICS therapy. A study of ICS-naive patients would have

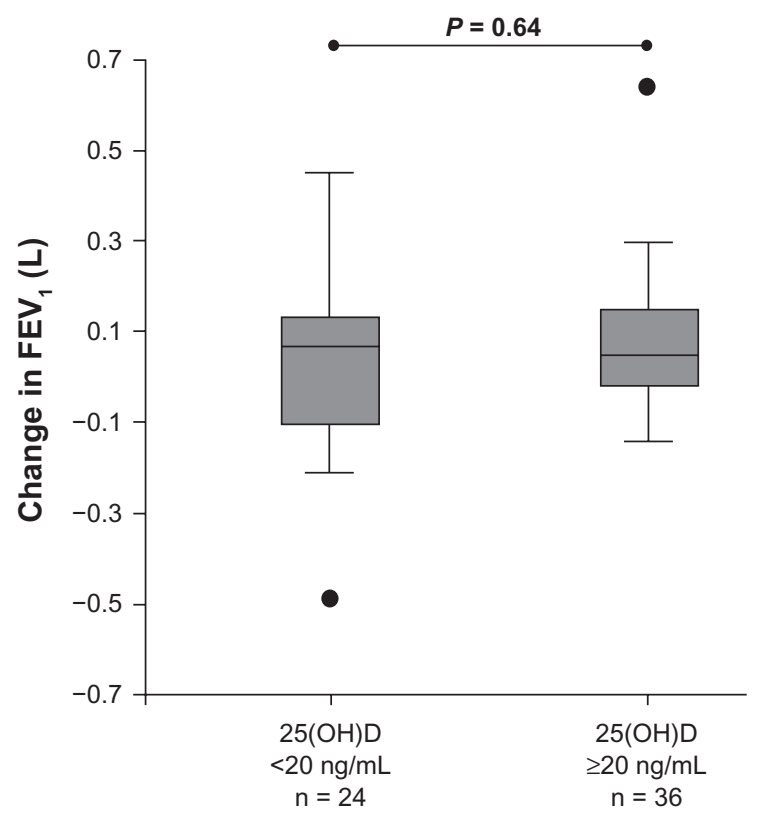

Figure 4 Boxplots of distributions in FEV, responses to ICS among study participants with vitamin $D$ deficiency $[25(\mathrm{OH}) D<20 \mathrm{ng} / \mathrm{mL}]$ versus no deficiency. Wilcoxon rank-sum test used for calculation of $P$ value.

Abbreviations: 25(OH)D, 25-hydroxyvitamin D; FEV , forced expiratory volume in I second; ICS, inhaled corticosteroid.

eliminated the need for a wash-out, but such a study was felt to be unfeasible for a single-center study, due to a high rate of use of ICS in patients with COPD (nearly 50\% in our recruited sample).

Another limitation of our study is that nonspirometric outcomes were not assessed, so an analysis of $25(\mathrm{OH}) \mathrm{D}$ relationships to outcomes such as acute exacerbations or respiratory health status could not be performed. Compared with patients without COPD, patients with COPD are also at increased risk of diseases such as cardiovascular disease, osteoporosis, and skeletal muscle dysfunction, which are all diseases which have been associated with low 25(OH)D levels. ${ }^{18}$ As such, these are areas that require further investigation.

Our data confirm previous observations regarding a high prevalence of what is traditionally considered a suboptimal $25(\mathrm{OH}) \mathrm{D}$ level of $<30 \mathrm{ng} / \mathrm{mL}$. We were not able to explain the reasons for low $25(\mathrm{OH}) \mathrm{D}$ levels, as we did not collect information on common factors affecting vitamin D status, such as dietary supplement use, sunlight exposure, and skin pigmentation. We also note that while we found a high prevalence of $25(\mathrm{OH}) \mathrm{D}$ levels $<30 \mathrm{ng} / \mathrm{mL}$ in our sample of patients with COPD, general population samples have also demonstrated a high prevalence of low 25(OH)D levels. Among 13,369 US participants in the National Health and Nutrition Examination Survey (NHANES) between 2001-2004, 77\% had levels $<30 \mathrm{ng} / \mathrm{mL} .{ }^{19}$ 
In summary, there was a high prevalence of low blood $25(\mathrm{OH}) \mathrm{D}$ levels in a sample of patients with severe COPD, and these $25(\mathrm{OH}) \mathrm{D}$ levels were not associated with short-term $\mathrm{FEV}_{1}$ responses to ICS therapy.

\section{Disclosure}

This study was supported by the Minnesota Veterans Research Institute (Investigator Grant to Dr Kunisaki) and National Institutes of Health (T32 HL07741 to Dr Kunisaki and UL1 RR024150 to Mayo Clinic).

\section{References}

1. Riancho JA, Gonzalez Macias J, Del Arco C, et al. Vertebral compression fractures and mineral metabolism in chronic obstructive lung disease. Thorax. 1987;42:962-966.

2. Shane E, Silverberg SJ, Donovan D, et al. Osteoporosis in lung transplantation candidates with end-stage pulmonary disease. Am J Med. 1996; 101: 262-269.

3. Forli L, Halse J, Haug E, et al. Vitamin D deficiency, bone mineral density and weight in patients with advanced pulmonary disease. J Intern Med. 2004;256:56-62.

4. Janssens W, Bouillon R, Claes B, et al. Vitamin D deficiency is highly prevalent in COPD and correlates with variants in the vitamin D-binding gene. Thorax. 2010;65:215-220.

5. Kunisaki KM, Niewoehner DE, Singh RJ, et al. Vitamin D status and longitudinal lung function decline in the Lung Health Study. Eur Respir J. $2010 \mathrm{Jul}$ 1. [Epub ahead of print].

6. Brehm JM, Schuemann B, Fuhlbrigge AL, et al. Serum vitamin D levels and severe asthma exacerbations in the Childhood Asthma Management Program study. J Allergy Clin Immunol. 2010;126:52-58.e5.

7. Brehm JM, Celedon JC, Soto-Quiros ME, et al. Serum vitamin D levels and markers of severity of childhood asthma in Costa Rica. Am J Respir Crit Care Med. 2009;179:765-771
8. Chinellato I, Piazza M, Sandri M, et al. Vitamin D serum levels and markers of asthma control in Italian children. J Pediatr. 2010 Sep 25. [Epub ahead of print].

9. Xystrakis E, Kusumakar S, Boswell S, et al. Reversing the defective induction of IL-10-secreting regulatory T cells in glucocorticoid-resistant asthma patients. J Clin Invest. 2006;116:146-155.

10. Sutherland ER, Goleva E, Jackson LP, et al. Vitamin D levels, lung function, and steroid response in adult asthma. Am J Respir Crit Care Med. 2010;181:699-704.

11. Searing DA, Zhang Y, Murphy JR, et al. Decreased serum vitamin D levels in children with asthma are associated with increased corticosteroid use. J Allergy Clin Immunol. 2010;125:995-1000.

12. Kunisaki KM, Rice KL, Janoff EN, et al. Exhaled nitric oxide, systemic inflammation, and the spirometric response to inhaled fluticasone propionate in severe chronic obstructive pulmonary disease: a prospective study. Ther Adv Respir Dis. 2008;2:55-64.

13. Standardization of Spirometry, 1994 Update. American Thoracic Society. Am J Respir Crit Care Med. 1995;52:1107-1136.

14. Hankinson JL, Odencrantz JR, Fedan KB. Spirometric reference values from a sample of the general US population. Am J Respir Crit Care Med. 1999;159:179-187.

15. Calverley P, Pauwels R, Vestbo J, et al. Combined salmeterol and fluticasone in the treatment of chronic obstructive pulmonary disease: a randomised controlled trial. Lancet. 2003;361:449-456.

16. Szafranski W, Cukier A, Ramirez A, et al. Efficacy and safety of budesonide/formoterol in the management of chronic obstructive pulmonary disease. Eur Respir J. 2003;21:74-81.

17. Aaron SD, Vandemheen KL, Fergusson D, et al. Tiotropium in combination with placebo, salmeterol, or fluticasone salmeterol for treatment of chronic obstructive pulmonary disease: a randomized trial. Ann Intern Med. 2007;146:545-555.

18. Holick MF. Vitamin D deficiency. N Engl J Med. 2007;357:266-281.

19. Ginde AA, Liu MC, Camargo CA Jr. Demographic differences and trends of vitamin D insufficiency in the US population, 1988-2004. Arch Intern Med. 2009;169:626-632.
International Journal of COPD

\section{Publish your work in this journal}

The International Journal of COPD is an international, peer-reviewed journal of therapeutics and pharmacology focusing on concise rapid reporting of clinical studies and reviews in COPD. Special focus is given to the pathophysiological processes underlying the disease, intervention programs, patient focused education, and self management protocols.

\section{Dovepress}

This journal is indexed on PubMed Central, MedLine and CAS. The manuscript management system is completely online and includes a very quick and fair peer-review system, which is all easy to use. Visit $\mathrm{http}: / /$ www.dovepress.com/testimonials.php to read real quotes from published authors. 